\title{
Vanillin production from native softwood lignin in the presence of tetrabutylammonium ion
}

\author{
Misaki Maeda ${ }^{1} \cdot$ Takashi Hosoya $^{1} \cdot$ Koichi Yoshioka $^{1} \cdot$ Hisashi Miyafuji ${ }^{1} \cdot$ Hiroyuki Ohno $^{2} \cdot$ Tatsuhiko Yamada $^{3}$
}

Received: 9 May 2018 / Accepted: 31 August 2018 / Published online: 1 November 2018

(c) The Japan Wood Research Society 2018

\begin{abstract}
Vanillin is one of the industrially important compounds that can be produced from lignin. This study presents production of vanillin and vanillic acid (oxidized form of vanillin) through aerobic oxidation of Japanese cedar (Cryptomeria japonica) at $120{ }^{\circ} \mathrm{C}$ for $72 \mathrm{~h}$ in aqueous alkali solutions with several $\mathrm{Bu}_{4} \mathrm{~N}^{+}$and $\mathrm{OH}^{-}$concentrations $(1.25,2.50$, and $3.75 \mathrm{~mol} / \mathrm{L})$, where $\mathrm{Bu}_{4} \mathrm{~N}^{+}$is an enhancer of the vanillin formation reported in our previous study. The concentrations of $\mathrm{Bu}_{4} \mathrm{~N}^{+}$and $\mathrm{OH}^{-}$were adjusted by the additions of $\mathrm{Bu}_{4} \mathrm{NCl}$ and solid $\mathrm{NaOH}$ into the base medium $\mathrm{Bu}_{4} \mathrm{NOH} \cdot 30 \mathrm{H}_{2} \mathrm{O}$, which forms $1.25 \mathrm{~mol} / \mathrm{L}$ aqueous solution of $\mathrm{Bu}_{4} \mathrm{NOH}$ at the elevated temperature. Vanillin and vanillic acid were produced with the maximum yields of 21.0 and $1.7 \mathrm{wt} \%$ (lignin-base), respectively, at the $1.25 \mathrm{~mol} / \mathrm{L} \mathrm{Bu}_{4} \mathrm{~N}^{+}$and $3.75 \mathrm{~mol} / \mathrm{L} \mathrm{OH}^{-}$concentrations. This vanillin yield is close to that obtained by the alkaline nitrobenzene oxidation $(26.5 \mathrm{wt} \%)$, indicating significantly high selectivity of our lignin degradation with $\mathrm{Bu}_{4} \mathrm{~N}^{+}$toward vanillin formation. We also proposed a novel $\mathrm{Bu}_{4} \mathrm{NOH} \cdot 30 \mathrm{H}_{2} \mathrm{O}-$ free reaction medium, where $\mathrm{Bu}_{4} \mathrm{NOH} \cdot 30 \mathrm{H}_{2} \mathrm{O}$ as the base medium were substituted with an aqueous solution of $\mathrm{Bu}_{4} \mathrm{NCl}$ and $\mathrm{NaOH}$ to avoid using expensive $\mathrm{Bu}_{4} \mathrm{NOH} \cdot 30 \mathrm{H}_{2} \mathrm{O}$. The treatment of the Japanese cedar with this alternative medium exhibited the moderately decreased vanillin yield of $14.6 \mathrm{wt} \%$, which is, however, much higher than the vanillin yield obtained with a simple $1.25 \mathrm{~mol} / \mathrm{L} \mathrm{NaOH}$ solution.
\end{abstract}

Keywords Lignin $\cdot$ Aerobic oxidation $\cdot$ Vanillin $\cdot$ Quaternary ammonium $\cdot$ Alkali

\section{Introduction}

Chemical conversion of lignin, an aromatic polymer consisting $20-35 \%$ of lignocellulose, into industrially valuable compounds is one of the hottest topics in the research field of biorefinery. Among various candidate products to be produced from lignin, vanillin is a highly promising compound because of versatility in its uses not only as a fragrance but

Electronic supplementary material The online version of this article (https://doi.org/10.1007/s10086-018-1766-0) contains supplementary material, which is available to authorized users.

Hisashi Miyafuji

miyafuji@kpu.ac.jp

1 Graduate School of life and Environmental Sciences, Kyoto prefectural University, Kyoto, Japan

2 Graduate School of engineering department, Tokyo University of Agriculture and Technology, Koganei, Japan

3 Forestry and Forest Products Research Institute, Tsukuba, Japan also as a starting material of pharmaceuticals and synthetic polymers [1-3]. Vanillin is almost ubiquitous in the product mixture from various biomass conversion processes [4-14], which suggests that vanillin is located at one of the major minima on the potential energy map of lignin degradation. This idea also justifies vanillin production from lignin and related raw materials.

Industrial vanillin production from lignin has been carried out since the 1950s by aerobic oxidation of sodium lignosulfonate (waste from sulfite pulping) in the presence of $\mathrm{NaOH}[15,16]$. Until the 1990s this method was the most dominant for worldwide vanillin production. However, in spite that the lignin-based process efficiently utilizes renewable wastes $[17,18]$, most of the present industrial vanillin production relies on petrol-derived chemicals, mostly guaiacol produced from phenol [19].

This ironical switching of the raw materials in vanillin production is attributed to complicated wastewater management required for the lignin-based process and tedious purification procedure originated essentially from low yield of vanillin from lignosulfonate, usually $\sim 5 \%[16,20]$. 
Considering the alternatives, if the above problems are fixed by further improvement of the process-for instance, if the yield of vanillin is improved to compensate the disadvantages - it is still possible that the lignin-based method recapture the dominant position for the world vanillin supply. Needless to mention, in view of the current global environmental issues, the vanillin production from renewable resource is much more favorable than those relying on fossil resources.

Alkaline nitrobenzene oxidation (AN oxidation) is currently the most selective method to convert lignin into vanillin and its related compounds [21, 22]. However, considering the toxic nature of nitrobenzene and its reduced products, it is not realistic to put this method into industrial application, although the yield obtained with AN oxidation can be a good reference to measure the performance of a newly developed lignin conversion method. To this end, we have been developing a nitrobenzene-free method for vanillin production that gives the target compound with higher yield than the current $\mathrm{NaOH}$-based process.

Our previous study have revealed that various lignin samples produce low molecular weight (MW) compounds, mainly vanillin and vanillic acid, with high selectivity through aerobic oxidation at $120^{\circ} \mathrm{C}$ in the $1.25 \mathrm{~mol} / \mathrm{L}$ aqueous solution of tetrabutylammonium hydroxide $\left(\mathrm{Bu}_{4} \mathrm{NOH}\right)$, which is formed through melting of solid $\mathrm{Bu}_{4} \mathrm{NOH} \cdot 30 \mathrm{H}_{2} \mathrm{O}$ at the elevated temperature [23]. As the aqueous solution of $\mathrm{NaOH}$ with the same $\mathrm{OH}^{-}$concentration as that of the $\mathrm{Bu}_{4} \mathrm{NOH}$ aq shows only much lower selectivity toward the low MW compounds, it is most likely that the $\mathrm{Bu}_{4} \mathrm{~N}^{+}$cation enhance their formation through the aerobic oxidation. Unlike the AN oxidation, the active oxidant in our reaction system is gaseous $\mathrm{O}_{2}$, which is of course not toxic and does not leave any harmful compounds after its consumption.

According to the above information, it is easy to expect that the selectivity toward the low MW compounds is greatly influenced by the $\mathrm{Bu}_{4} \mathrm{~N}^{+}$and $\mathrm{OH}^{-}$concentrations. It is especially important to clarify what improvement will be made when their concentrations are increased to more than $1.25 \mathrm{~mol} / \mathrm{L}$. However, control of the concentrations is not trivial since intensive removal of crystal water from $\mathrm{Bu}_{4} \mathrm{NOH} \cdot 30 \mathrm{H}_{2} \mathrm{O}$ results in degradation of $\mathrm{Bu}_{4} \mathrm{~N}^{+}$. This consideration led us to the idea that the concentrations of $\mathrm{Bu}_{4} \mathrm{~N}^{+}$and $\mathrm{OH}^{-}$are increased by the addition of a $\mathrm{Bu}_{4} \mathrm{~N}$ salt $\left(\mathrm{Bu}_{4} \mathrm{NX}\right)$ and $\mathrm{NaOH}$ to $\mathrm{Bu}_{4} \mathrm{NOH} \cdot 30 \mathrm{H}_{2} \mathrm{O}$. With such addition, the $\mathrm{Bu}_{4} \mathrm{NOH} \cdot 30 \mathrm{H}_{2} \mathrm{O}$-based reaction solution is destined to contain the salt $\mathrm{NaX}$ as an artifact. The first part of this study investigates the effects of the $\mathrm{NaX}$ with $\mathrm{Cl}^{-}, \mathrm{Br}^{-}$, and $\mathrm{SO}_{4}{ }^{2-}$ being selected as the anionic part. We will then discuss our major results on the effects of the concentrations of $\mathrm{Bu}_{4} \mathrm{~N}^{+}$and $\mathrm{OH}^{-}$with $\mathrm{Bu}_{4} \mathrm{NCl}$ being selected as the $\mathrm{Bu}_{4} \mathrm{~N}^{+}$ source. The final part of this study propose a new reaction medium composed only of $\mathrm{Bu}_{4} \mathrm{NCl}$ and $\mathrm{NaOH}$, which medium exhibits high performance for the lignin conversion without an expensive reagent $\mathrm{Bu}_{4} \mathrm{NOH} \cdot 30 \mathrm{H}_{2} \mathrm{O}$.

\section{Experimental}

\section{Materials}

$\mathrm{Bu}_{4} \mathrm{NOH} \cdot 30 \mathrm{H}_{2} \mathrm{O}(\geq 98 \%)$ was purchased from SigmaAldrich Co. $\mathrm{Bu}_{4} \mathrm{NCl}, \mathrm{NaOH}$ (solid), $\mathrm{NaCl}, \mathrm{NaBr}$, and $\mathrm{Na}_{2} \mathrm{SO}_{4}$ were provided from Wako pure chemical Co. Milled wood lignin was prepared according to the literature [24]. The particle size of the Japanese cedar (Cryptomeria japonica) wood flour was $90-180 \mu \mathrm{m}$.

\section{Preparation of reaction media}

Solid $\mathrm{Bu}_{4} \mathrm{NOH} \cdot 30 \mathrm{H}_{2} \mathrm{O}$ was first liquefied at $30{ }^{\circ} \mathrm{C}$ to give a $1.25 \mathrm{M}$ aqueous solution of $\mathrm{Bu}_{4} \mathrm{NOH}$. To the $\mathrm{Bu}_{4} \mathrm{NOH}$ solution were put additives $[\mathrm{NaCl}(145 \mathrm{mg}, 2.5 \mathrm{mmol})$, $\mathrm{NaBr}$ (257.5 mg, $2.5 \mathrm{mmol}), \mathrm{Na}_{2} \mathrm{SO}_{4}(355 \mathrm{mg}, 2.5 \mathrm{mmol})$, $\mathrm{Bu}_{4} \mathrm{NCl}(693.8-1387.5 \mathrm{mg}, 2.5-5.0 \mathrm{mmol})$, and $\mathrm{NaOH}$ (100-200 mg, 2.5-5.0 mmol)]. The resulting mixture was then stirred for $4 \mathrm{~h}$ to form a homogeneous solution, which was directly used as the reaction medium for lignin degradation. In case only $\mathrm{Bu}_{4} \mathrm{NCl}$ and $\mathrm{NaOH}$ were used as the reaction medium, $100-300 \mathrm{mg}(2.5-7.5 \mathrm{mmol})$ of $\mathrm{NaOH}$ was added to a $1.25-3.75 \mathrm{M}$ aqueous solution of $\mathrm{Bu}_{4} \mathrm{NCl}$ and the solution was stirred for $4 \mathrm{~h}$ in the same manner as that presented above.

\section{Degradation of lignin samples and analysis of the reaction mixture}

Lignin sample $(14 \mathrm{mg})$ and $2.0 \mathrm{~mL}$ of a reaction medium prepared from the above method were put in a $25 \mathrm{~mL}$ glass tube. After the tube was tightly sealed, the reaction solution was heated up to $120{ }^{\circ} \mathrm{C}$ in an oil bath and stirred for $72 \mathrm{~h}$. After the tube was cooled with cold water, $800 \mu \mathrm{L}$ of the $2.0 \mathrm{~g} / \mathrm{L}$ 1,5-dihydroxy-1,2,3,4-tetrahydronaphthalene/ethanol solution was added as an internal standard. $100 \mu \mathrm{L}$ of the resulting reaction mixture was taken and put into $900 \mu \mathrm{L}$ of acetonitrile containing $1.5 \%$ acetic acid. The solution was filtrated and used as a sample for HPLC analysis.

The HPLC analysis was carried out with HPLC system (Shimadzu, Ltd., Kyoto, Japan) equipped with pump (LC10AD), column oven (CTO-10A), and ultraviolet-visible detector (SPD-10A) set at $280 \mathrm{~nm}$. Analytical conditions were a Cadenza CD-C18 (Imtakt, Co., Kyoto, Japan) column, a flow rate of $0.8 \mathrm{~mL} / \mathrm{min}$, a $1.5 \%$ acetic acid aq/acetonitrile eluent $(90 / 10 \rightarrow 45 / 550-30 \mathrm{~min}, 45 / 55 \rightarrow 0 / 100$ 30-35 min, 0/100 35-40 min, 0/100 $\rightarrow$ 90/10 40-45 min, 90/10 45-60 min) after passing through the degasser 
(DGU-14A, Shimadzu, Ltd., Kyoto, Japan), and a column temperature of $30^{\circ} \mathrm{C}$.

\section{Results and discussion}

\section{Effects of inorganic salt}

The major purpose of this paper is to carry out degradation of lignin with increased concentrations of $\mathrm{Bu}_{4} \mathrm{~N}^{+}$and $\mathrm{OH}^{-}$by adding $\mathrm{Bu}_{4} \mathrm{NX}$ and $\mathrm{NaOH}$ to the $1.25 \mathrm{M}$ aqueous solution of $\mathrm{Bu}_{4} \mathrm{NOH}$, namely $\mathrm{Bu}_{4} \mathrm{NOH} \cdot 30 \mathrm{H}_{2} \mathrm{O}$ in liquid form. As mentioned above, $\mathrm{NaX}$ destined to exist in the $\mathrm{Bu}_{4} \mathrm{NX}-\mathrm{NaOH}$-added system may affect the degradation of lignin and decrease the product yields. To this end, we first investigated the effects of $\mathrm{NaCl}, \mathrm{NaBr}$ and $\mathrm{Na}_{2} \mathrm{SO}_{4}$ on the degradation of the milled wood lignin prepared from Japanese cedar (Cryptomeria japonica). The milled wood lignin is a lignin sample supposedly retaining the original lignin structure in the wood.

A control experiment without the addition of the sodium salts was carried out at $120{ }^{\circ} \mathrm{C}$ for $72 \mathrm{~h}$ under air, for which conditions were proposed as the optimum ones in our previous report [23]. As presented in the HPLC chromatogram in Fig. 1 the mixture obtained after degradation contained vanillin, vanillic acid, acetoguaiacone, $p$-hydroxybenzaldehyde, and guaiacol with several minor unidentified compounds, which is in accordance with the results in our previous study. Further quantification showed that the yields of vanillin, vanillic acid, acetoguaiacone, and $p$-hydroxybenzaldehyde were $10.5,2.5,0.49$ and $0.38 \mathrm{wt} \%$, respectively, indicating

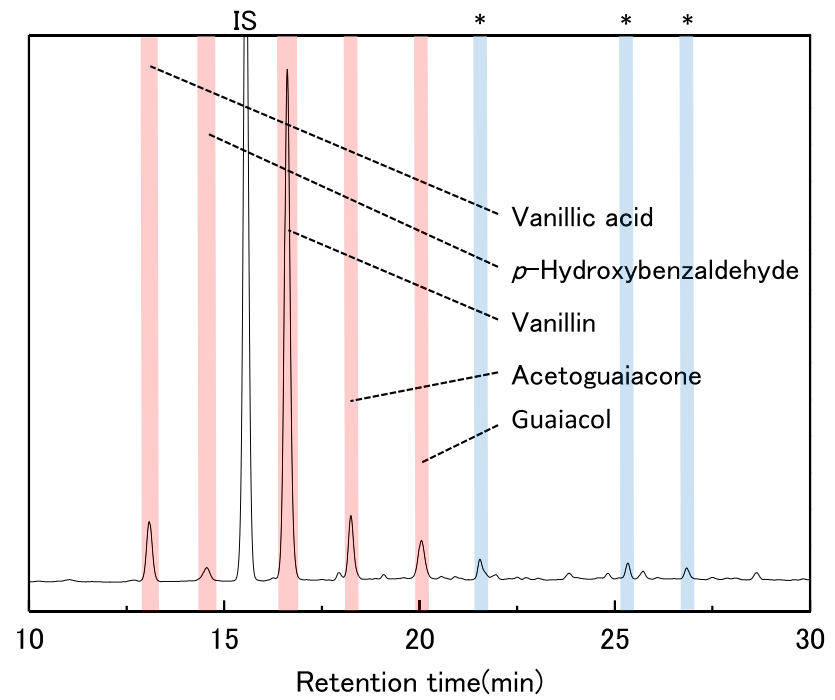

Fig. 1 HPLC chromatogram of the reaction mixture obtained from the degradation of the milled wood lignin in the $1.25 \mathrm{~mol} / \mathrm{L} \mathrm{Bu} \mathrm{BOH}_{4} \mathrm{NOH}$ aq at $120^{\circ} \mathrm{C}$ for $72 \mathrm{~h}$. IS: Internal standard (1,5-dihydroxy-1,2,3,4-tetrahydronaphthalene). Unidentified peaks are shown with an asterisk that the low molecular weight products are composed most of vanillin and vanillic acid. We will thus focus on these two compounds, vanillin and vanillic acid, hereafter.

We then degraded the milled wood lignin with the addition of $\mathrm{NaCl}, \mathrm{NaBr}$, and $\mathrm{Na}_{2} \mathrm{SO}_{4}$. The concentration of the salt was taken to be the same as that of $\mathrm{Bu}_{4} \mathrm{~N}^{+}, 1.25 \mathrm{~mol} / \mathrm{L}$. As shown in Fig. 2, in the $\mathrm{NaCl}$-added system, the yield of vanillin decreased to $9.2 \mathrm{wt} \%$ from $10.5 \mathrm{wt} \%$ with a slight increase in the yield of vanillic acid $(2.5 \mathrm{wt} \% \rightarrow 2.6 \mathrm{wt} \%)$. The total yield of vanillin and vanillic acid was accordingly decreased by $1.1 \mathrm{wt} \%$ by the $\mathrm{NaCl}$ addition. In the $\mathrm{NaBr}$ added system, although the total yield (11.8 wt\%) of vanillin and vanillic acid was similar to that of the $\mathrm{NaCl}$-added system, the formation of vanillin became more dominant over that of vanillic acid. In general, halide anions have reducibility and its ability becomes stronger in heavier anions. Thus, this trading-off behavior observed between vanillic acid and vanillin is explained by relatively strong reducibility of $\mathrm{Br}^{-}$. In the $\mathrm{Na}_{2} \mathrm{SO}_{4}$-added system, the yields of both vanillin and vanillic acid decreased from 10.5 and $2.5 \%$ to 10.1 and $1.2 \%$, resulting in the $1.7 \%$ decrease in their total yield, which decrease was the largest of the three salt-added systems.

The above results indicate that the yields of vanillin and vanillic acid are decreased by the addition of the sodium salts, but the decrease is more moderate in $\mathrm{NaCl}$ and $\mathrm{NaBr}$ than in $\mathrm{Na}_{2} \mathrm{SO}_{4}$. As $\mathrm{NaBr}$ changes the ratio of vanillin and vanillic acid (see above) —although the detailed mechanisms for the influence of these sodium salts are not clear at present-it can be said that $\mathrm{NaCl}$ has the smallest influence on the lignin degradation. From these considerations, we concluded that $\mathrm{Cl}^{-}$should be adapted as the anionic part of the $\mathrm{Bu}_{4} \mathrm{~N}$ salt to increase the $\mathrm{Bu}_{4} \mathrm{~N}^{+}$concentration of the 1.25 $\mathrm{M} \mathrm{Bu}_{4} \mathrm{NOH}$ aq. In the next section, we make concrete discussion on the influence of the $\mathrm{Bu}_{4} \mathrm{NCl}$ and $\mathrm{NaOH}$ additions on the lignin degradation.

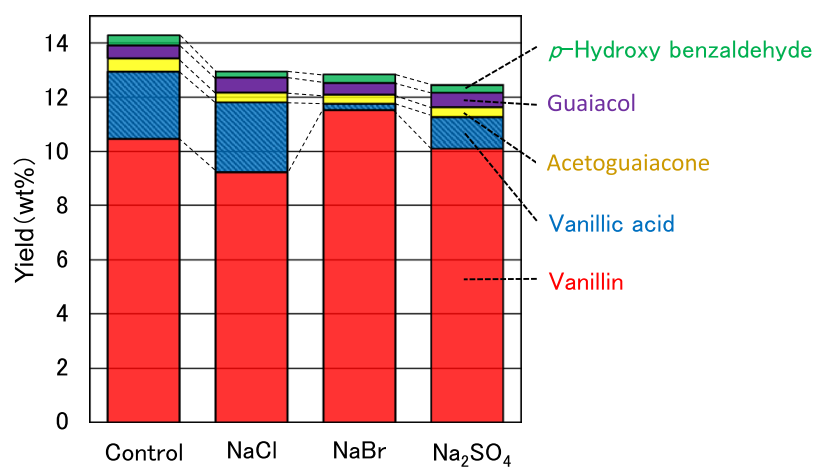

Fig. 2 Yield of major products from the milled wood lignin after the degradation in the $1.25 \mathrm{~mol} / \mathrm{L} \mathrm{Bu}_{4} \mathrm{NOH}$ aq at $120{ }^{\circ} \mathrm{C}$ for $72 \mathrm{~h}$ with $\mathrm{NaCl}, \mathrm{NaBr}$, and $\mathrm{Na}_{2} \mathrm{SO}_{4}$. The concentrations of the $\mathrm{Cl}^{-}, \mathrm{Br}^{-}$, and $\mathrm{SO}_{4}{ }^{2-}$ were taken to be the same as that of $\mathrm{Bu}_{4} \mathrm{~N}^{+}(1.25 \mathrm{~mol} / \mathrm{L})$. See Table S1 in Supporting information for detailed yields of the identified compounds 


\section{$\mathrm{Bu}_{4} \mathrm{NCl}$ - and $\mathrm{NaOH}$-added systems}

Degradation of lignin was carried out under the additions $\mathrm{Bu}_{4} \mathrm{NCl}$ and $\mathrm{NaOH}$ to the $1.25 \mathrm{M} \mathrm{Bu}_{4} \mathrm{NOH}$ solution. In this case, we employed the wood flour as a potential raw material. Figure 3a summarizes the yields of vanillin and vanillic acid in the systems in which solid $\mathrm{NaOH}$ was added to the $1.25 \mathrm{M} \mathrm{Bu}_{4} \mathrm{NOH}$ solution to increase the $\mathrm{OH}^{-}$concentration. The yields of vanillin and vanillic acid considerably increased along with the addition of $\mathrm{NaOH}$ and reached 7.2 and $0.6 \mathrm{wt} \%$, respectively, at the $\mathrm{OH}^{-}$concentration of $3.75 \mathrm{~mol} / \mathrm{L}$. Note that the increase in the yield of vanillin was much more remarkable than that of vanillic acid: the yield of vanillin increased from 3.9 to $7.2 \%$ upon going from the $\mathrm{OH}^{-}$concentration of $1.25-3.75 \mathrm{~mol} / \mathrm{L}$, whereas the yield of vanillic acid remained relatively stable $(0.5-0.6 \%)$. This suggests that vanillic acid is produced by a reaction pathway different from that of vanillin and the vanillin-forming pathway is more sensitive to the $\mathrm{OH}^{-}$concentration, but further investigation is required for details. It is also noted that treatment of vanillin in the $1.25 \mathrm{M} \mathrm{Bu}_{4} \mathrm{NOH}$ solution at $120{ }^{\circ} \mathrm{C}$ for $72 \mathrm{~h}$ under air resulted in almost quantitative recovery of vanillin, which suggests that vanillin is considerably stable under the conditions employed and not likely to be a precursor of vanillic acid.

As shown in Fig. $3 \mathrm{a}-\mathrm{c}$, when the $\mathrm{Bu}_{4} \mathrm{~N}^{+}$concentration was increased from 1.25 to $3.75 \mathrm{~mol} / \mathrm{L}$ by adding $\mathrm{Bu}_{4} \mathrm{NCl}$ with the $\mathrm{OH}^{-}$concentration being fixed at $1.25 \mathrm{~mol} / \mathrm{L}$, the total yield of vanillin and vanillic acid increased from 4.4 to $5.8 \mathrm{wt} \%$. This increase in the yield was less remarkable than that caused by the increase in the $\mathrm{OH}^{-}$concentration. There are three possible explanations for this result, as far as we think of. The first is that the increase in the $\mathrm{Cl}^{-}$concentration by the addition of $\mathrm{Bu}_{4} \mathrm{NCl}$ suppressed the formation of vanillin and vanillic acid. In the previous section, we have shown that the addition of $\mathrm{NaCl}$ moderately reduces the yield of vanillin, which also supports this possibility. The second is that the effect of the viscosity of the reaction solution increased by the $\mathrm{Bu}_{4} \mathrm{NCl}$ addition. Aqueous solutions of $\mathrm{Bu}_{4} \mathrm{NOH}$ exhibit viscosity much higher than that of water [25] and the $\mathrm{Bu}_{4} \mathrm{NCl}$ addition is expected to further increase the viscosity of the reaction solutions. Our previous report has shown that oxygen supply to the reaction solution is indispensable for the production of vanillin and vanillic acid (Yamamoto et al., 2016 [23]). The increased viscosity of the reaction solution should inhibit the stirring of the reaction solution, resulting in oxygen deprivation of the reaction system. The last possibility is that the increase in the $\mathrm{Bu}_{4} \mathrm{~N}^{+}$concentration is not as effective as that in the $\mathrm{OH}^{-}$concentration from the view point of fundamental mechanisms of the lignin degradation in the present reaction system, although the detailed mechanisms has not been clear yet. Further investigation to elucidate the molecular role of $\mathrm{Bu}_{4} \mathrm{~N}^{+}$will provide clearer views for these three hypotheses.

When the $\mathrm{OH}^{-}$concentration was increased with the $\mathrm{Bu}_{4} \mathrm{~N}^{+}$concentration being fixed at $2.50 \mathrm{~mol} / \mathrm{L}$ (Fig. 3b), the significant increase in the yields of vanillin and vanillic acid was not observed unlike the case with the $\mathrm{Bu}_{4} \mathrm{~N}^{+}$ concentration of $1.25 \mathrm{~mol} / \mathrm{L}$ (Fig. 3a). Furthermore, when the $\mathrm{Bu}_{4} \mathrm{~N}^{+}$concentration was $3.75 \mathrm{~mol} / \mathrm{L}$, the increase in the $\mathrm{OH}^{-}$concentration resulted in a decrease in the yields of vanillin and vanillic acid (Fig. 3c). We would be able to explain these results in similar ways to those presented above. That is, the increased $\mathrm{Cl}^{-}$concentration causes the decrease in the yields; the increase in the $\mathrm{OH}^{-}$concentration becomes ineffective for improving the yields in higher $\mathrm{Bu}_{4} \mathrm{~N}^{+}$concentrations due to presently unknown mechanistic reasons.

From the above results it was revealed that the formation of vanillin and vanillic acid proceeds most efficiently when the concentrations of $\mathrm{OH}^{-}$and $\mathrm{Bu}_{4} \mathrm{~N}^{+}$were set to be 3.75 and $1.25 \mathrm{~mol} / \mathrm{L}$, respectively, although the detailed
Fig. 3 Yields of vanillin and vanillic acid after the degradation in several $\mathrm{Bu}_{4} \mathrm{NOH}$-based reaction media at $120{ }^{\circ} \mathrm{C}$ for $72 \mathrm{~h}$. a) The concentrations of $\mathrm{Bu}_{4} \mathrm{~N}^{+}$and $\mathrm{OH}^{-}$were changed by the addition of $\mathrm{Bu}_{4} \mathrm{NCl}$ and $\mathrm{NaOH}$, respectively. See Table S2 in Supporting information for detailed yields of the vanillin and vanillic acid

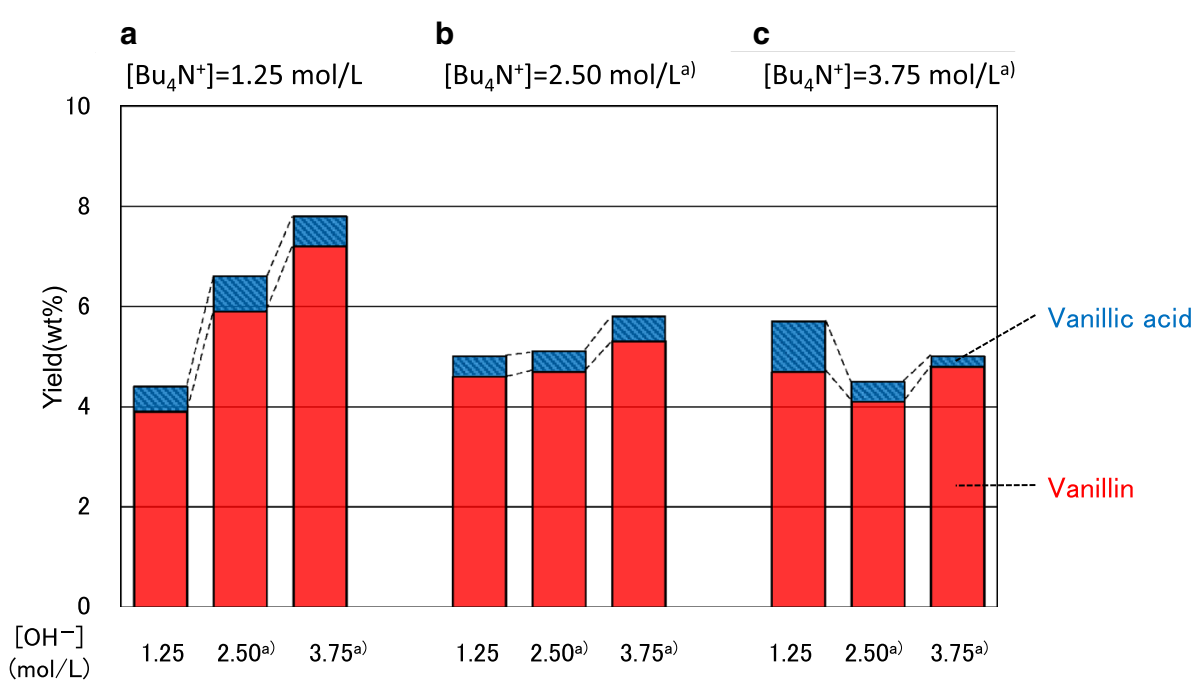


mechanisms underlying this phenomena are unknown at the moment. Under these ion concentrations, the yields of vanillin and vanillic acid were 7.2 and $0.6 \%$, respectively. As the Klason lignin content of the wood was $34.3 \%$, the yields of vanillin and vanillic acid were 21.0 and $1.7 \%$, based on the lignin amount in the wood, which indicates high selectivity of the lignin conversion in our $\mathrm{Bu}_{4} \mathrm{NOH}-\mathrm{NaOH}$ system. It is also noted that the yields of vanillin and vanillic acid achieved in our reaction system is close to those reported for the alkaline nitrobenzene oxidation (vanillin: $9.1 \mathrm{wt} \%$ and vanillic acid: $0.4 \mathrm{wt} \%$ ) [23], which is currently the most highly selective lignin degradation method.

\section{$\mathrm{Bu}_{4} \mathrm{NCl}-\mathrm{NaOH}\left(\mathrm{Bu}_{4} \mathrm{NOH}-\right.$ free$)$ systems}

The $\mathrm{Bu}_{4} \mathrm{NOH}$-based solutions used so far have excellent performance for selective lignin degradation, as a result of the positive effects exhibited by the $\mathrm{Bu}_{4} \mathrm{~N}^{+}$cation under alkaline conditions. This led us to the idea that $\mathrm{Bu}_{4} \mathrm{NCl}$ may be used as a source of $\mathrm{Bu}_{4} \mathrm{~N}^{+}$instead of $\mathrm{Bu}_{4} \mathrm{NOH} \cdot 30 \mathrm{H}_{2} \mathrm{O}$, which is a relatively expensive reagent. In this section, we propose a new reaction system employing an aqueous solution composed of only $\mathrm{Bu}_{4} \mathrm{NCl}$ and $\mathrm{NaOH}$ without $\mathrm{Bu}_{4} \mathrm{NOH} \cdot 30 \mathrm{H}_{2} \mathrm{O}$. The $\mathrm{Bu}_{4} \mathrm{~N}^{+}$concentration of this $\mathrm{Bu}_{4} \mathrm{NCl}-\mathrm{NaOH}$ system alternative for the $\mathrm{Bu}_{4} \mathrm{NOH}$ one was set to be $1.25 \mathrm{~mol} / \mathrm{L}$, in which the total maximum yield of vanillin and vanillic acid was achieved in the previous section (Fig. 3a).

Figure 4 shows the yields of vanillin and vanillic acid obtained in the $\mathrm{Bu}_{4} \mathrm{NCl}-\mathrm{NaOH}$ system. In the $\mathrm{Bu}_{4} \mathrm{NCl}-\mathrm{NaOH}$ system with the different $\mathrm{OH}^{-}$concentrations of 1.25 and $3.75 \mathrm{~mol} / \mathrm{L}$, the total yields of vanillin and vanillic acid were $3.7 \mathrm{wt} \%$ (vanillin: $3.2 \mathrm{wt} \%$, vanillic acid: $0.5 \mathrm{wt} \%$ ) and $5.2 \mathrm{wt} \%$ (vanillin: $5.1 \mathrm{wt} \%$, vanillic acid:0.1 wt $\%$ ), respectively. These yields were lower than those in the case of the corresponding $\mathrm{Bu}_{4} \mathrm{NOH}$-based system with the same $\mathrm{Bu}_{4} \mathrm{~N}^{+}$and $\mathrm{OH}^{-}$concentrations (Fig. 2). One of the possible causes of this decrease in the yield is that, as already presented above, $\mathrm{Cl}^{-}$masked the positive effect of $\mathrm{Bu}_{4} \mathrm{~N}^{+}$, by which the yields of the compounds were decreased.

Our previous study showed that, when the wood flour was degraded in a simple alkaline solution, $1.25 \mathrm{~mol} / \mathrm{L} \mathrm{NaOH}$ aq, vanillin and vanillic acid were produced with the yields of 1.1 and 0.83 wt\%, as shown in Fig. 4. In the alternative $\mathrm{Bu}_{4} \mathrm{NCl}-\mathrm{NaOH}$ system-although the yields were lower than those in the $\mathrm{Bu}_{4} \mathrm{NOH}$-based system (see above)-they are still much higher than those in the $\mathrm{NaOH}$ system. These results suggest that, considering $\mathrm{Bu}_{4} \mathrm{NCl}$ is much less expensive than $\mathrm{Bu}_{4} \mathrm{NOH} \cdot 30 \mathrm{H}_{2} \mathrm{O}$, the aqueous solutions consisting only of $\mathrm{Bu}_{4} \mathrm{NCl}$ and $\mathrm{NaOH}$ have significant ability for selective lignin conversion, although further efforts to improve the yields are necessary to employ this system as a substitute for $\mathrm{Bu}_{4} \mathrm{NOH} \cdot 30 \mathrm{H}_{2} \mathrm{O}$-based system.

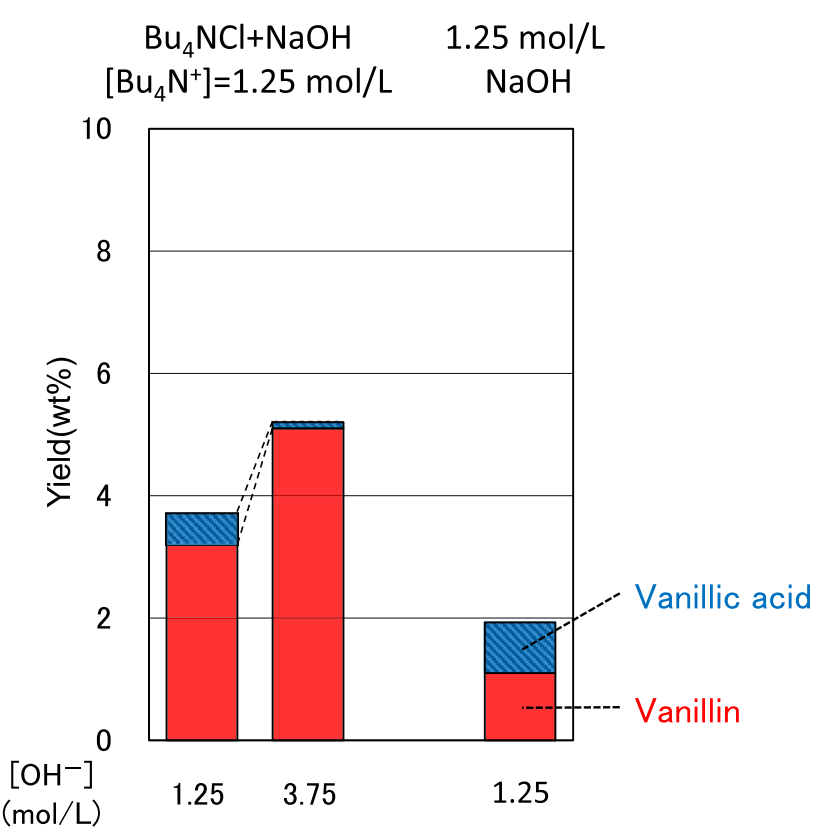

Fig. 4 Yields of vanillin and vanillic acid after the degradation of the wood flour in the aqueous solutions of $\mathrm{Bu}_{4} \mathrm{NCl}(1.25 \mathrm{~mol} / \mathrm{L})$ and $\mathrm{NaOH}(1.25$ and $3.75 \mathrm{~mol} / \mathrm{L})$ at $120{ }^{\circ} \mathrm{C}$ for $72 \mathrm{~h}$, as compared with those after the degradation in the $1.25 \mathrm{~mol} / \mathrm{L} \mathrm{NaOH}$ aq under the same conditions [23]. See Table S2 in Supporting information for detailed yields of the vanillin and vanillic acid

\section{Conclusions}

Our preliminary investigation on the effects of the sodium salts on the degradation behavior of the milled wood lignin suggested that $\mathrm{NaCl}$ have the smallest influence on the lignin degradation in the $\mathrm{Bu}_{4} \mathrm{NOH}$ aq. We thus selected $\mathrm{Bu}_{4} \mathrm{NCl}$ as the additive for the $\mathrm{Bu}_{4} \mathrm{NOH}$ aq to increase the concentration of $\mathrm{Bu}_{4} \mathrm{~N}^{+}$. The experiments with various concentrations of $\mathrm{Bu}_{4} \mathrm{~N}^{+}$and $\mathrm{OH}^{-}$indicated that vanillin and vanillic acid were obtained with the maximum yields (7.2 and $0.6 \mathrm{wt} \%$, respectively) at the $\left[\mathrm{Bu}_{4} \mathrm{~N}^{+}\right]=1.25 \mathrm{~mol} / \mathrm{L}$ and $\left[\mathrm{OH}^{-}\right]=3.75 \mathrm{~mol} / \mathrm{L}$. These yields are similar to those exhibited by the alkaline nitrobenzene oxidation, which is the most selective method for vanillin formation from lignin at present and frequently employed as an analytical method for chemical properties of lignin. This indicates excellent selectivity achieved in our lignin degradation method with the $\mathrm{Bu}_{4} \mathrm{NOH}$ aq and the additives. In addition, it was shown that the aqueous solutions of $\mathrm{Bu}_{4} \mathrm{NCl}$ and $\mathrm{NaOH}$ can be substituted for $\mathrm{Bu}_{4} \mathrm{NOH} \cdot 30 \mathrm{H}_{2} \mathrm{O}$ which is an expensive reaction medium.

Acknowledgements This work was supported by the Technologies for Creating Next-Generation Agriculture, Forestry and Fisheries under the Cross-Ministerial Strategic Innovation Promotion Program (SIP) administered by Council for Science, Technology and Innovation 
(CSTI), Japan, and a Grant-in-Aid for Young Scientists (B) (No. 17K18008) from the Japan Society for the Promotion of Science.

\section{References}

1. Brianna MU, Andrea MK (2016) Strategies for the conversion of lignin to high-value polymeric materials: review and perspective. Chem Rev 116:2275-2306

2. Audrey L, Etienne G, Stéphane C, Stéphane G, Henri C (2016) From lignin-derived aromatic compounds to novel biobased polymers. Macromol Rapid Comm 37:9-28

3. Francisco G, Dobado AJ (2010) Lignin as renewable raw material. Chem Sus Chem 3:1227-1235

4. Jiang G, Nowakowski JD, Bridgwater VA (2010) Effect of the temperature on the composition of lignin pyrolysis products. Energy Fuels 24:4470-4475

5. Kang S, Li X, Fan J, Chang J (2013) Hydrothermal conversion of lignin. Renew Sust Energ Rev 27:546-558

6. Borges da Silva EA, Zabkova M, Araujo JD, Cateto CA, Barreiro MF, Belgacem MN, Rodrigues AE (2009) An integrated process to produce vanillin and lignin-based polyurethanes from kraft lignin. Chem Eng Res Des 87:1276-1292

7. Jose DPA, Carlos AG, Alirio ER (2009) Structured packed bubble column reactor for continuous production of vanillin from kraft lignin oxidation. Catal Today 147:330-335

8. Jose DPA, Carlos AG, Alirio ER (2010) Vanillin production from lignin oxidation in a batch reactor. Chem Eng Res Des 88:1024-1032

9. Paula CRP, Carina EC, Alirio ER (2013) Oxidation of lignin from eucalyptus globulus pulping liquors to produce syringaldehyde and vanillin. Ind Eng Chem Res 52:4421-4428

10. Mathias LA, Rodrigues EA (1995) Production of vanillin by oxidation of pine kraft lignins with oxygen. Holzofrsch 49:273-278

11. Claire F, Alvaro M, Alirio R (1996) Kinetic of vanillin production from kraft lignin oxidation. Ind Eng Chem Res 35:28-36

12. Guozzhan J, Daniel JN, Anthony VB (2010) Effect of the temperature on the composition of lignin pyrolysis products. Energy Fuels 24:4470-4475

13. Shimin K, Xianglan L, Juan F, Jie C (2013) Hydrothermal conversion of lignin. Renew Sust Energ Rev 27:546-558
14. Ogawa S, Miyafuji H (2015) Reaction behavior of milled wood lignin in an ionic liquid, 1-ethyl-3-methylimidazolium chloride. J Wood Sci 61:285-291

15. Forss GK, Talka TE, Fremer KE (1986) Isolation of vanillin from alkaline oxidized spent sulfite liquor. Ind Eng Chem Prod Res Dev 25:103-108

16. Hocking MB (1997) Vanillin: synthetic flavoring from spent sulfite liquor. J Chem Edu 74:1055-1059

17. Tomlinson G 2nd, Hibbert H (1936) Studies on lignin and related compounds. XXIV. The formation of vanillin from waste sulfite liquor. J Am Chem Soc 58:345-348

18. Tomlinson G 2nd, Hibbert H (1936) Studies on lignin and related compounds. XXIV. Mechanism of vanillin formation from spruce lignin sulfonic acids in relation to lignin structure. J Am Chem Soc 58:348-353

19. Triumph Venture Capitals Limited (2004) Part three-Aroma chemicals derived from petrochemical feedstocks. In: Study into the establishment of an aroma and fragrance fine chemicals value chain in South Africa, Triumph Venture Capitals Limited, South Africa

20. Vidal JP (2006) Vanillin. In: Kirk-Othmer encyclopedia of chemical technology. Wiley, Hoboken. https://doi.org/10.1002/04712 38961.2201140905191615.a01.pub2

21. Chang HM, Allan GG (1971) Oxidation. In: Sarkanen KV, Ludwig $\mathrm{CH}$ (eds) Lignins: occurrence, formation, structure, and reactions. Wiley Interscience, New York, pp 433-485

22. Schultz TP, Templeton MC (1986) Proposed mechanism for the nitrobenzene oxidation of lignin. Holzforsch 40:93-97

23. Yamamoto K, Hosoya T, Yoshioka K, Miyafuji H, Ohno H, Yamada T (2017) Tetrabutylammonium hydroxide 30-hydrate as novel reaction medium for lignin conversion. ACS Sus Chem Eng 5:10111-10115

24. Björkman A (1956) Studied on finely divided wood. part1. Extraction of lignin with neutral solvents. Svensk Papperstidn 59:477-485

25. Safdar R, Omar AZ, Ismail LB, Bari A, Lal B (2015) Measurement and correlation of physical properties of aqueous solutions of tetrabutylammonium hydroxide, piperazine and their aqueous blends. Chin J Chem Eng 23:1811-1818 